\title{
New records and new species of Metopina Macquart (Diptera: Phoridae) from Tasmania
}

\author{
R. Henry L. DISNEY \\ Department of Zoology, University of Cambridge, Downing Street, Cambridge, CB2 3EJ, U. K.; \\ e-mail: rhld2@hermes.cam.ac.uk
}

\begin{abstract}
Metopina glandula sp. n., M. lacrimula sp. n., M. microquartus sp. n., and two species of males not yet linked to their females are described from Tasmania.
\end{abstract}

Key words: Diptera, Phoridae, Metopina, new species, Australia

\section{INTRODUCTION}

While on a visit to Fern Tree in Tasmania in 2002 Phoridae were collected in a garden in Grays Road. Among the specimens obtained were numbers of Metopina Macquart, whose species recognition is based on females in the first instance. Apart from two previously known species, the females of three species proved to be new and are described below. Males of two species caught on the same occasions are given code letters only until they can be linked to their females. In the key to Australasian species (Disney 2003) it should be noted that at couplet 11 lead 1 should be directed to couplet 12 (not 11) and lead 2 to couplet 13 (not 12).

\section{MATERIAL AND METHODS}

The specimens were collected in water traps and preserved in $70 \%$ ethanol and were subsequently slide mounted in Berlese Fluid (Disney 2001). Holotypes are deposited in the Tasmanian Museum and Art Gallery in Hobart (TMH) and paratypes in the University of Cambridge Museum of Zoology (UCMZ).

\section{SYSTEMATICS}

\section{Metopina climieorum Disney, 1994}

Metopina climieorum Disney 1994: 122.

Material examined. 2 males, 1 female, Fern Tree, Grays Road, 2-3 \& 11-12 March 2002.

This species was previously known from mainland Australia, New Zealand and Sandy Bay, Hobart in Tasmania (Disney 1994), and since recorded from Taiwan (unpublished).

\section{Metopina glandula sp. $\mathbf{n}$.}

(Figs 1-5)

Female. Head as Fig. 1. Thorax brown with a pale propleuron and sternopleuron. Anterior hairs of scutellum about as strong as those at rear of scutum. Abdominal tergites and venter as Figs 2-4. Legs with brown femora and tibiae but those of front legs paler as well as distal half of front coxa. All tarsi dusky yellow. Hind leg as Fig. 5. Wings 1.2-1.3 mm long. Costal index 
0.51. Vein 3 subequal to slightly thicker than costa. Membrane lightly tinged brown. Haltere knob dark brown.

Etymology. The name refers to the protuberances of dense microtichia at the posterolateral regions of abdominal segment 5 that indicate the presence of a pair of small glands.

Recognition. In the key to Australasian Metopina (Disney 2003) it runs to couplet 9, lead 1, but its tergites 4-6 are clearly different.

Material examined. Holotype female, TASMANIA, Fern Tree, Grays Road, 1-2 March 2002 (TMH, 25-50).

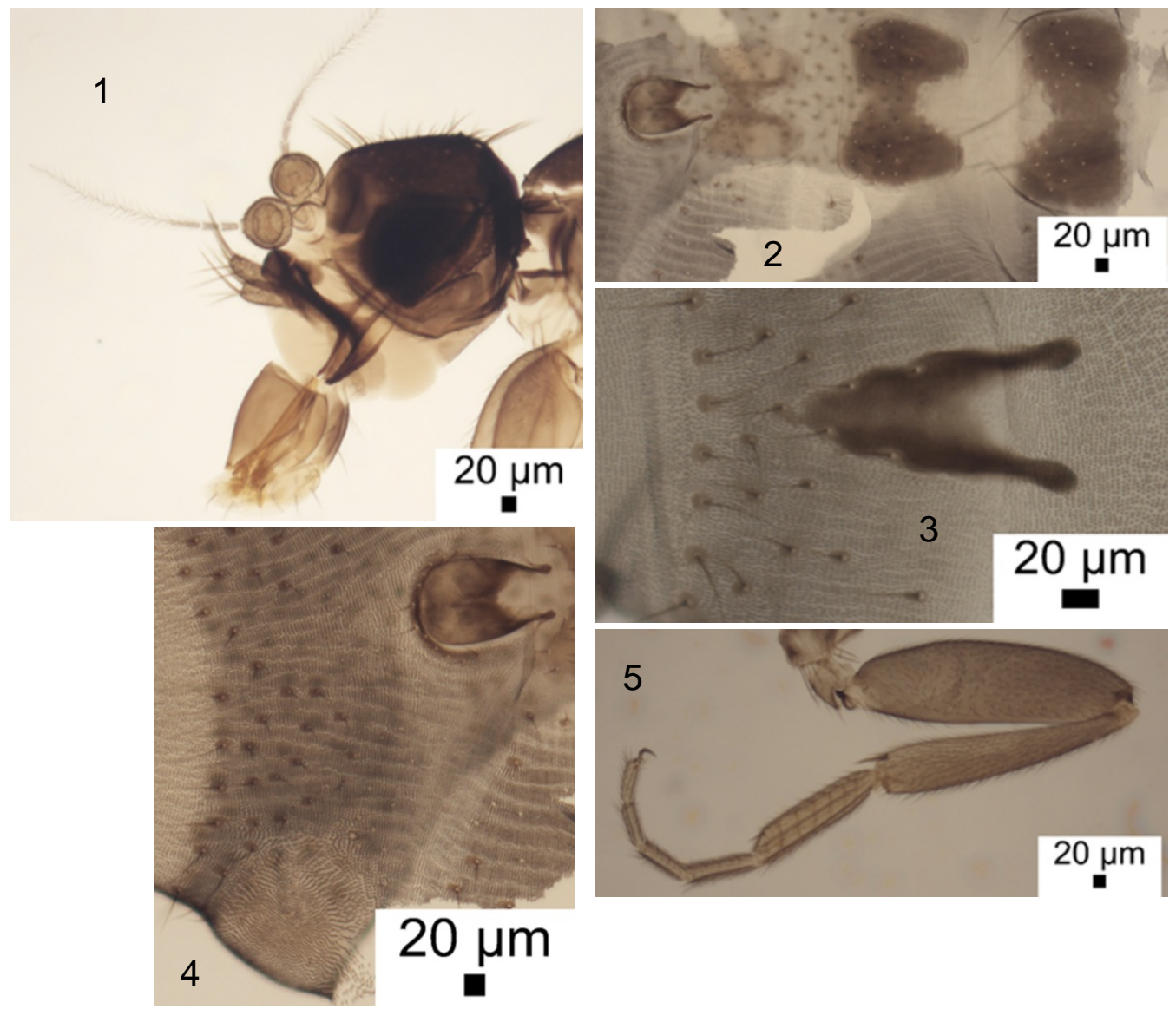

Figs 1-5. Metopina glandula female. 1 - head, 2 - abdominal tergites 3 to 5, 3 - tergite 6, 4 - segment 5 with T 5 and right gland, 5 - hind leg.

\section{Metopina lacrimula sp. n.}

(Figs 6-9)

Female. Head as Fig. 6. Thorax brown. Anterior hairs of scutellum at most as strong as those at rear of scutum. Abdominal tergites and venter as Figs 7-8. Legs with all femora and hind tibia brown, the rest being paler and all tarsi dusky yellow. Hind femur to basitarsus as Fig. 9. Wings $1.5 \mathrm{~mm}$ long. Costal index 0.5. Vein 3 subequal to slightly thicker than costa. Membrane lightly tinged brown. Haltere knob dark brown. 
Etymology. The name refers to the little flap of abdominal tergite 5.

Recognition. In the key to Australasian Metopina (Disney 2003) it runs to couplet 7, lead 2, but its tergites 4 and 5 are clearly different.

Material examined. Holotype female, TASMANIA, Fern Tree, Grays Road, 2-3 March 2002 (TMH, 25-51). Paratype female, same data (UCMZ, 25-51).

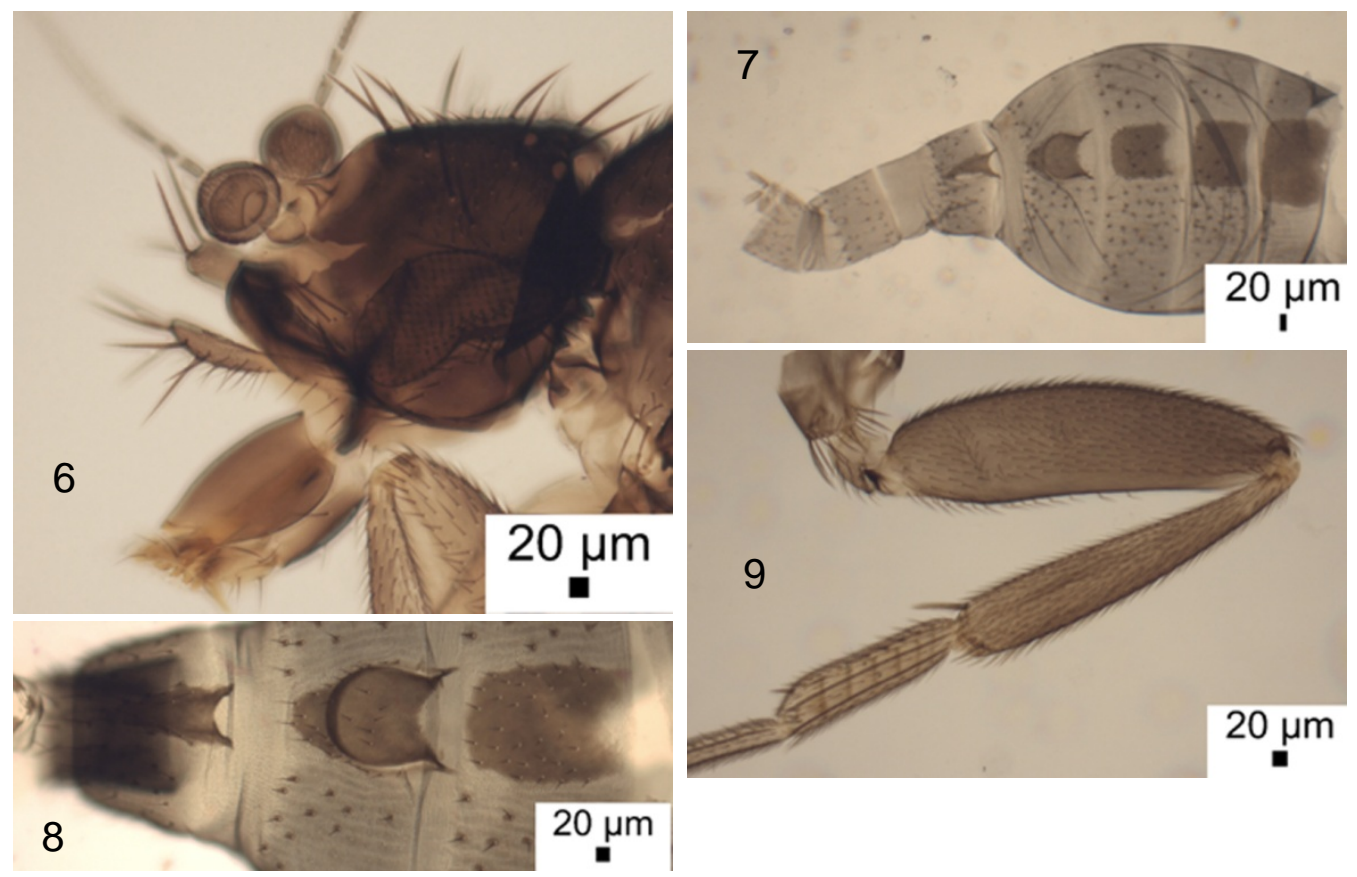

Figs 6-9. Metopina lacrimula female. 6 - head, 7 - abdominal tergites, 8 - tergites 4 to 6, 9 - hind femur to basitarsus.

\section{Metopina microquartus sp. $\mathbf{n}$.}

(Figs 10-14)

Female. Head as Fig. 10. Thorax with brown scutum, scutellum and posterior portion of mesopleuron, the rest largely pale. Anterior hairs of scutellum at most as strong as those at rear of scutum. Abdominal tergites and venter as Figs 11-13. Legs at most with light brown femora and tibiae and pale tarsi. Front tarsus with posterodorsal hair palisades on segments 1-4 only. Hind femur and tibia as Fig. 14. Wings $1.6 \mathrm{~mm}$ long. Costal index 0.5. Vein 3 clearly thicker than costa. Membrane lightly tinged brown. Haltere knob dark brown dorsally but pale ventrally.

Etymology. The name refers to the small size of abdominal tergite 4 .

Recognition. In the key to Australasian Metopina (Disney, 2003) it runs to couplet 9, lead 1 , but is immediately distinguished by the greatly elongated flap of tergite 5 and its unusually small tergite 4 .

Material examined. Holotype female, TASMANIA, Fern Tree, Grays Road, 11-12 March 2002 (TMH, 25-60). Paratype female, same locality, 1-2 March 2002 (UCMZ, 25-50). 


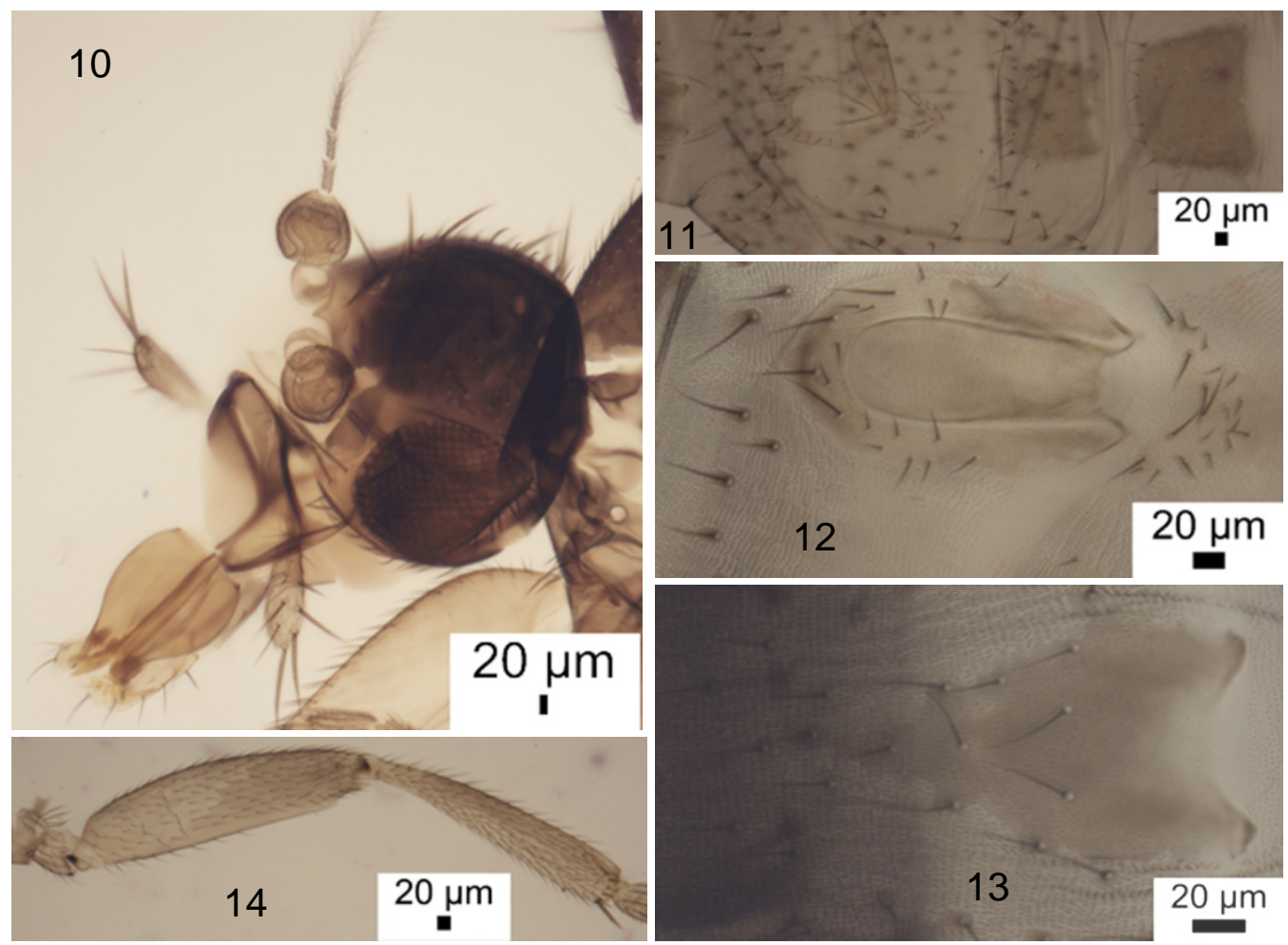

Figs 10-14. Metopina microquartus female. 10 - head, 11 - abdominal tergites 3 to 5, 12 - tergite 5, 13 - tergite 6, 14 - hind femur and tibia.

\section{Metopina Species AE Disney}

Metopina Species AE Disney 2003: 616 (male).

Material examined. 2 males, TASMANIA, Fern Tree, Grays Road, 2-3 March 2002.

Previously known from Western Australia. This is possibly the male of Metopina lacrimula.

\section{Metopina Tas A}

(Figs 15-18)

Male. Head as Fig. 15. Thorax brown dorsally but mainly pale on sides. Anterior hairs of scutellum at most as strong as those at rear of scutum. Apart from darker hind femur and tibia the legs are dusky yellow with paler tarsi. Front tarsus as Fig. 16. Hind femur as Fig. 17. Wings $0.7 \mathrm{~mm}$ and basal half as Fig. 18. Costal index 0.35. Haltere knob brown.

Recognition. In the key to Australasian Metopina (Disney, 2003) it runs to couplet 20 lead 1, but species AQ has six bristles on the frons between the upper supra-antennals and anterior ocellus and its legs are much darker.

Material examined. Male, TASMANIA, Fern Tree, Grays Road, 1-2 March 2002 (TMH, 25-50). 


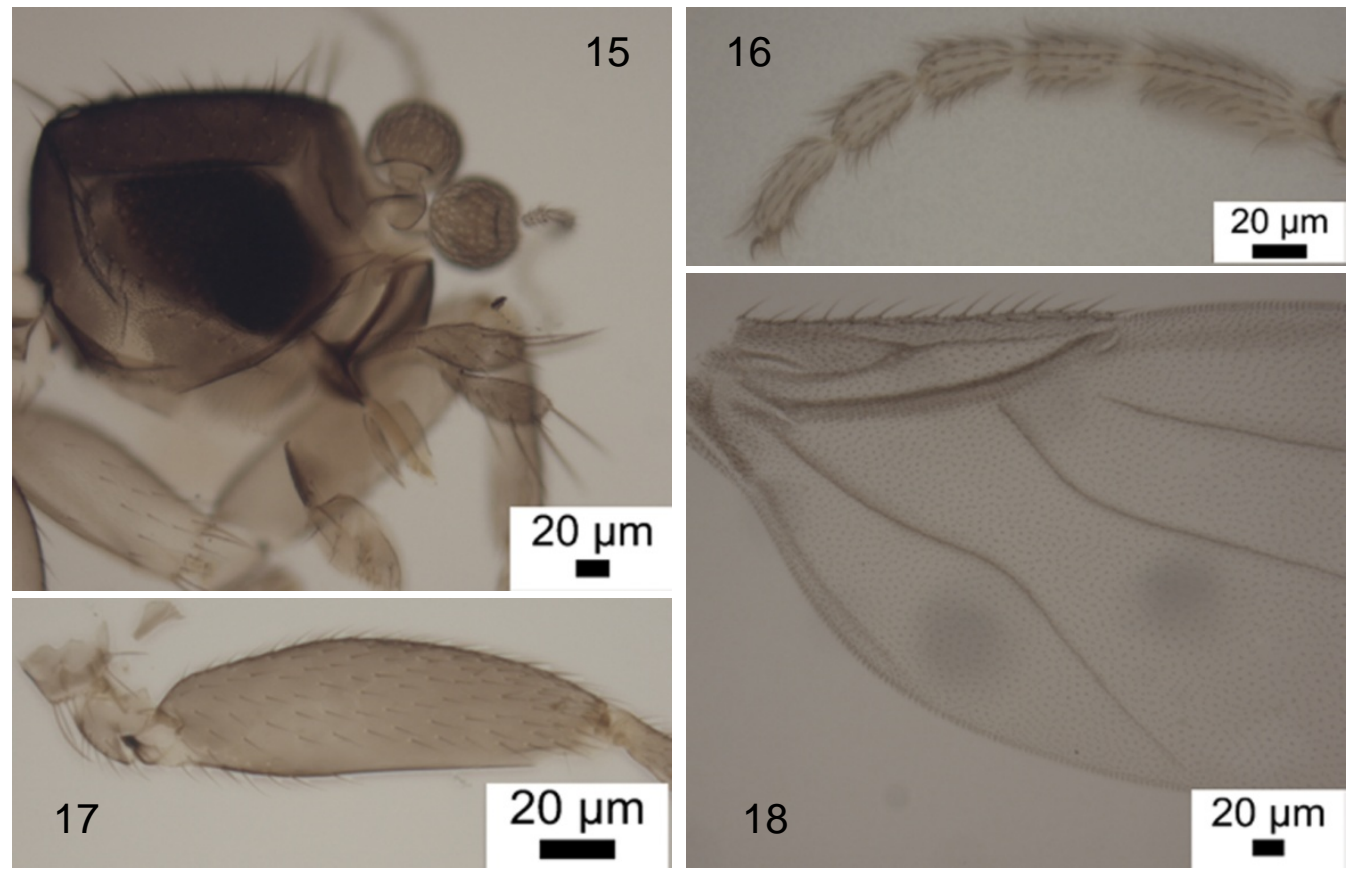

Figs 15-18. Metopina species TAS A male. 15 - head, 16 - front tarsus, 17 - hind femur, 18 - basal region of wing.

\section{Metopina Tas B}

(Figs 19-22)

Male. Frontal bristles as Fig. 19, with only small antials between the supra-antennals and anterior ocellus. Palp as Fig. 20. Postpedicels coloured as palps. Thorax with brown scutum, scutellum and posterior portion of mesopleuron, the rest largely pale. Anterior hairs of scutellum at most as strong as those at rear of scutum. Apart from darker hind femur and tibia the legs are progressively more dusky yellow with paler tarsi. Front tarsus as Fig. 21. Hind femur as Fig. 22. Wings $0.7 \mathrm{~mm}$ long. Costal index 0.35. The costa and vein 3 subequal in width. Membrane tinged gray. Haltere knob dark brown dorsally but paler ventrally.

Recognition. In the key to Australasian Metopina (Disney, 2003) it runs to couplet 20 lead 2, but species AE has six bristles on the frons between the upper supra-antennals and anterior ocellus and its costal index exceeds 0.45 .

Material examined. 2 males, TASMANIA, Fern Tree, Grays Road, 2-3 March 2002 (TMH, 25-50). 


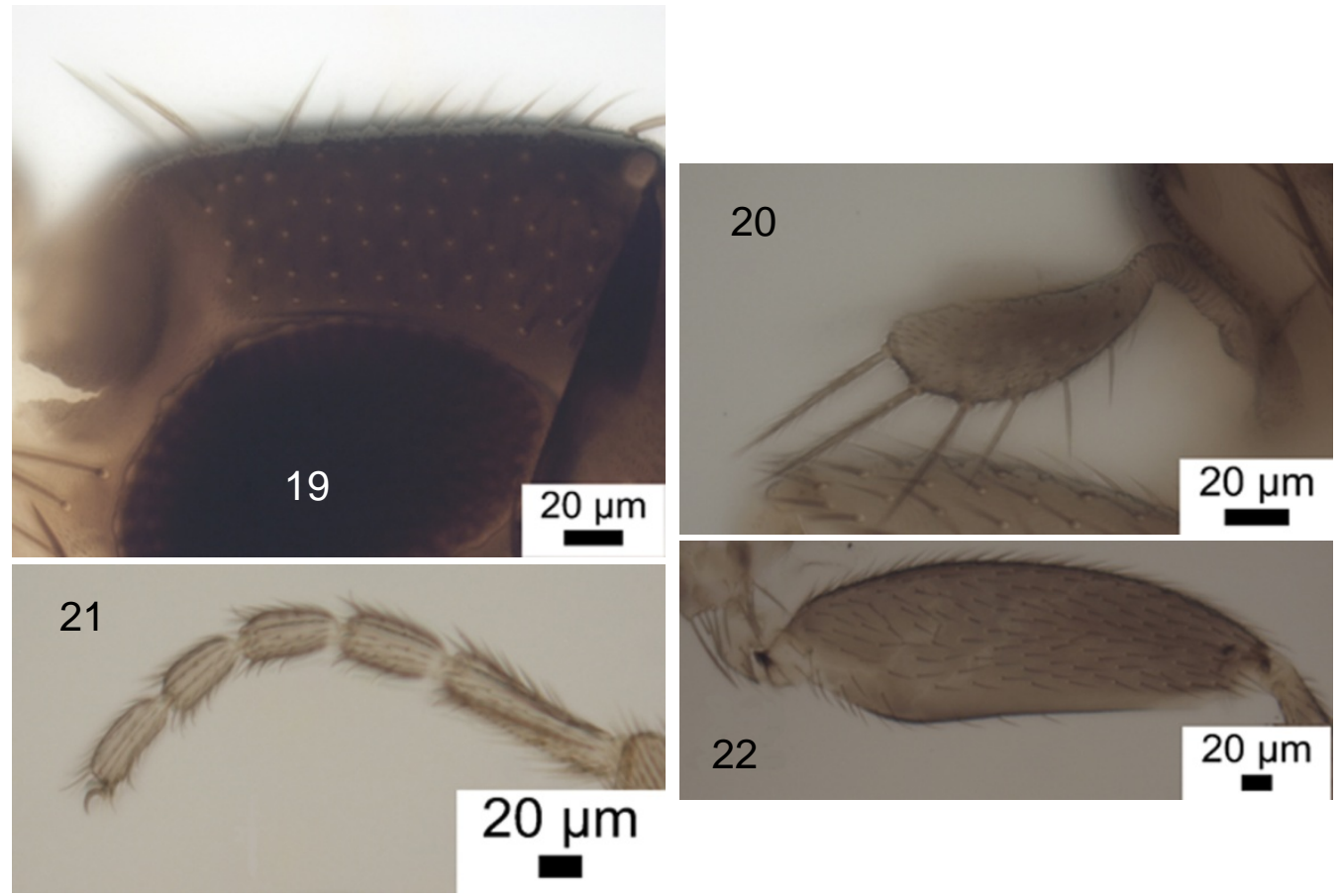

Figs 19-22. Metopina species TAS B male. 19 - frons showing the small antial bristle, 20 - palp, 21 - front tarsus, 22 - hind femur.

\section{ACKNOWLEDGEMENTS}

My studies of Phoridae are currently supported by a grant from the Balfour-Browne Trust Fund (University of Cambridge).

\section{REFERENCES}

Disney R. H. L. 1994. A new species and new records of Phoridae (Diptera) from New Zealand. Giornale Italiano di Entomologia 6: 119-124 (1992).

DiSNEY R. H. L. 2001. The preservation of small Diptera. Entomologist's Monthly Magazine 137: 155-159.

Disney R. H. L. 2003. Tasmanian Phoridae (Diptera) and some additional Australasian species. Journal of Natural History 37: 505-639.

\section{STRESZCZENIE}

[Uaktualnione dane i opisy nowych gatunków z rodzaju Metopina Macquart (Diptera: Phoridae) z Tasmanii]

W zebranym na Tasmanii materiale Phoridae zostały opisane trzy nowe dla nauki gatunki z rodzaju Metopina: M. glandula sp. n., M. lacrimula sp. n., M. microquartus sp. n. Ponadto, stwierdzono dwa samce i jedną samicę należące do gatunku Metopina climieorum, a także pięć samców z rodzaju Metopina o nieznanej dotychczas przynależności gatunkowej (Metopina Species AE, Metopina Tas A, Metopina Tas B). 